\title{
Mortality in childhood-onset type 1 diabetes: Nationwide population based data from Norway
}

\author{
Torild Skrivarhaug \\ Norwegian Childhood Diabetes Registry, Department of Paediatric Medicine, Women and Children's Division, \\ Oslo University Hospital \\ Correspondence: Torild Skrivarhaug, Department of Paediatric Medicine, Oslo University Hospital, PB 4950, 0424 Oslo \\ E-mail: torild.skrivarhaug@medisin.uio.noＴelephone: +47 22118765/23015648Ｔelefax: +47 22118663
}

\begin{abstract}
Type 1 diabetes with onset in childhood (0-14.9 years) represents one of the most frequent chronic diseases in children and young adults. Norway has one of the highest incidences of childhood onset type 1 diabetes in the world. Before introduction of insulin therapy in 1922, few children survived more than one to two years after clinical onset. When insulin came available, a major shift occurred in the distribution of causes of death in type 1 diabetic patients away from diabetic coma, which dominated the pre-insulin era, to renal and cardiac diseases. The disease is related to a significant burden to society and patients because most cases require lifelong treatment with insulin as well as day-to-day monitoring. Type 1 diabetes also confers increased risk of severe late complications such as renal failure, blindness, amputations, heart disease and stroke. Despite advances in diabetes treatment, type 1 diabetes is still associated with considerable premature mortality resulting from acute and chronic complications of diabetes and an increase in mortality at every age. Although the main cause of death in type 1 diabetes is long-term complications, an excess death rate has also been reported in subjects with short duration without signs of long-term complications.
\end{abstract}

\section{INTRODUCTION}

Third to Finland and Sweden, Norway has the highest incidence of childhood onset type 1 diabetes in the world (1). More than 300 children are diagnosed with type 1 diabetes in Norway each year, the annual incidence rate is 33-36/100 000 (2). Even in societies with well-organized health care systems and unrestricted access to treatment of diabetes and its complications, type 1 diabetes is associated with risk of premature death due to acute and late complications (3-8). Death after diabetes duration of 20 years has been related to renal complications and cardiovascular disease $(4,6,9$, 10 ). Early mortality has mainly been related to acute complications such as diabetic ketoacidosis (DKA) and severe hypoglycemia $(5,6,11)$. It has also been reported that young and apparently healthy individuals seem to have a significant risk of sudden death during sleep (6,12-14).

This article concerns the epidemiological data on mortality in childhood-onset type 1 diabetes from Norway, set in relationship to data from other countries. Valid reports on mortality in children with type 1 diabetes are rare, even sparser from Norway $(6,7)$.

One Norwegian study has documented a considerably increased risk of total and cardiovascular death in a young cohort of patients with childhood-onset type 1 diabetes, diagnosed in 1973-1982, after 24 years diabetes duration (6). The relative mortality was increased four times in this young cohort compared to the background population. The main cause of death in the total cohort was violent death (accidents, suicide and intoxication). When the cohort was divided in death before and after 30 years of age, the main death cause was acute complications in early years and cardiovascular events after the age of 30 years.

\section{DEATHS IN CHILDHOOD}

\section{Deaths at onset}

Globally. Children with type 1 diabetes in societies without access to insulin, blood-glucose monitoring, and health care services face a very high risk of dying in connection with the diagnosis of type 1 diabetes or soon after disease onset due to acute complications (mainly DKA). In many of these children it is likely that type 1 diabetes may have remained undiagnosed, being masked by a clinical picture of competing infectious diseases and malnutrition $(12,15)$.

In Norway, the awareness for type 1 diabetes is high among health personnel, probably due to the high incidence. Data on mortality in children at the onset of type 1 diabetes is sparse, but it is no reason to believe this to be high. It is reported two cases of death in children at diabetes onset during the first $48 \mathrm{~h}$ because of DKA with cerebral edema, during the seventies (6). The first description of the worldwide variation in the frequency of DKA at presentation of type 1 diabetes was recently published, reporting large variations that may, at least in part, be explained by different levels of disease awareness and healthcare provision (16). EURODIAB indicated that the frequency of DKA in Europe at diagnosis varied from $11 \%$ to $67 \%(17)$. The first published data from Norway on DKA at presentation of type 1 diabetes reported that $18.0 \%$ of the children had DKA; $17.0 \%$ of the boys and $18.3 \%$ of the girls (18).

\section{Risk factors for premature death}

The age at onset of diabetes may influence the risk of late complications. Several studies (19-21) indicate that young age at onset of diabetes can prolong the time until development of microalbuminuria, nephropathy, end stage renal disease, and other vascular complica- 
tions. It has been suggested that diagnosis during puberty could promote the development of chronic diabetes complications due to deterioration of glycemic control, rapid growth, and hormonal changes $(22,23)$. Better long term survival could thus be expected in people diagnosed before puberty.

The prognosis of type 1 diabetes with onset in childhood and adolescence may be improving with lower risk of severe complications and premature death, but young people with diabetes are still at considerable high risk of diabetic retinopathy, diabetic nephropathy, peripheral diabetic neuropathy, cardiovascular disease and premature death $(6,11,24,25)$. One recent study from Allegheny County, USA, reported a decline in total mortality rates for children diagnosed with type 1 diabetes at age $<18$ years in the period 1965 to 1979 (26). They also report a decline in mortality rates for acute complications and renal disease. In this study women had a $30 \%$ higher rate than men from all diabetes related causes.

\section{Causes of death in T1D; underreported and misclassified}

Diabetes is a major global cause of premature mortality that is widely underestimated. Only a minority of patients with diabetes die from a cause uniquely related to the condition such as DKA or hypoglycemia. Diabetes is known to be under-reported on death certificates as an underlying or contributing cause of death $(6,27$ 29). Cohort studies of subjects with a confirmed diabetes diagnosis, are the best way to assess the mortality risk among patients with diabetes.

When we classified causes of death in the Norwegian diabetes cohort, causes of death was registered and classified in two ways for different purposes (6): 1) Information on the cause of death was obtained from the death certificate and from the International Classification of Diseases (ICD) codes (30-32) for the underlying cause of death in the Cause of Death Registry. These data were used for comparing mortality rates with those of the background population. 2) Since the cause of death in patients with T1D is frequently misclassified $(6,33,34)$, the cause of death was also ascertained by a clinical review committee, critically assessing all available information including hospital records, outpatient records, police reports, death certificates, post-mortem reports and necropsy reports. The clinical review committee included three diabetologists.

\section{Violent death}

Violent death including accidents, suicide and intoxications are common among young people with type 1 diabetes, especially in males, in whom it was the greatest single cause of death under 30 years of age. In the age group 30-40 years it was exceeded only by cardiovascular disease (CVD) as cause of death (6).

\section{Acute metabolic complications}

Acute metabolic complications were the largest single cause of death under the age of 30 years in the total cohort (6). This is in keeping with a study from the UK (11). In the total Norwegian cohort, $15 \%$ died of DKA; two adolescents at diabetes onset, 13 had had diabetes for several years, $10 \%$ died of hypoglycemia (6).

\section{Renal death}

Renal disease has previous been identified as a major cause of death in patients with type 1 diabetes (35). In the Norwegian study, end-stage renal failure was responsible for $8 \%$ of all deaths (6). The standardized mortality ratio (SMR) was high for this cause, from which few deaths occur in patients without diabetes, especially at young age. At all ages the number of deaths certified to CVD exceeded those certified to renal disease.

\section{Cardiovascular death}

Several studies $(36,37)$ have found diabetes to be a greater risk factor for morbidity and mortality from cardiovascular death in women than in men. In Norway, the mortality rates from ischemic heart disease (IHD) in women were not only greater than for women without diabetes, but were also considerably higher than for men without diabetes (6). In the general population mortality from IHD was much higher in men than in women. In the Norwegian diabetes cohort the mortality from IHD was also higher in men than in women, in contrast to data from UK reporting no differences between the sexes under the age of 40 years (37).

\section{Dead-in-bed syndrome}

The so-called dead-in-bed syndrome refers to sudden death in young diabetic patients without any history of long-term complications. It is a rare, but dramatic condition. Autopsy is typically negative. The causes of death are by definition unknown, but a plausible theory is a death in hypoglycemia, since a history of nocturnal hypoglycemia is noted in most cases (14). Another theory is that fatal cardiac dysrhythmias are considered the cause of dead-in-bed syndrome, which might be provoked by an episode of hypoglycemia (38). One study assessing UK and the Scandinavian countries found that such deaths occurred in $6 \%$ of all deaths in diabetic patients younger than 40 years. The frequency may also be expressed as 2-6 events per 10,000 patient years (14). A study of mortality in Norwegian patients with type 1 diabetes under the age of 40 years, during the period 1981-1990, reported that $6.7 \%$ of the cases were "dead in bed" (39). Another Norwegian study reported that $3.4 \%$ of all the patients fulfilled the criteria of "dead in bed". In this study severe episodes of hypoglycemia was reported in $75 \%$ of the cases (40). In the Norwegian study previously presented in this paper $3.9 \%$ met the criteria of "dead in bed", three males and one female aged 12-24 years (6). The Norwegian numbers are less than observed by others $(12,41)$. A Swedish study reported dead-in-bed syndrome in $9 \%$ of the patients. Mean age at death in this group was 18.1 years (range 11.4-25.1) and mean diabetes duration 8.2 years (range 2.6-12.6) (12). 


\section{Increased relative mortality}

In the Norwegian cohort, the standardized mortality ratio (SMR) was four times higher in patients with childhood-onset type 1 diabetes compared to the background population, similar for both genders (6). Mortality from childhood-onset diabetes differs markedly from country to country. In recent studies $(3,12,42-44)$ from different countries, the SMR varies from 2.15 in Sweden to as high as 12.9 in Japan. Due to differences in methods, background populations and the populations studied, comparison should be done with caution.

Increased relative mortality in children 0-14 years Studies from developed countries have consistently reported that the relative mortality (all causes considered) in type 1 diabetes is of the magnitude of about 3 , corresponding to a mortality rate at about $1 / 1000$ patientyears at risk in children $0-14$ years $(6,12,44)$. The excess death in children is predominantly caused by acute complications (mainly DKA), infections, external causes, and unexplained deaths $(6,12,44,45)$. The literature indicate that mortality may be higher in countries with lower incidence levels $(42,45-47)$, suggesting that awareness and knowledge of treatment of type 1 diabetes in children may be an important factor (17). The literature is however not conclusive; EURODIAB reported that SMR varied between 0 to 4.7 between 12 different European countries, but found little relationship with the countries' incidence rate or gross domestic product (US\$ per capita) (5).

\section{CONCLUSION}

In conclusion, childhood-onset type 1 diabetes still carries an increased mortality risk when compared with the non-diabetic population in Norway. Violent deaths, acute metabolic complications and CVD are the main causes of deaths. This raises the importance of high awareness of psychological comorbidity in childhood-onset type 1 diabetes as well as to focus on late complications and premature death. In terms of preventable deaths, DKA among already diagnosed cases certainly belongs to this group.

\section{REFERENCES}

1. Soltesz G, Dahlquist GG. Global trends in childhood type 1 diabetes. Diabetes Atlas, 3rd Edn. 2012: 154-8.

2. Skrivarhaug T. Annual report 2009, The Norwegian Childhood Diabetes Registry, www.barnediabetes.no, 2010 .

3. Harjutsalo V, Forsblom C, Groop PH. Time trends in mortality in patients with type 1 diabetes: nationwide population based cohort study. BMJ 2011; 343: d5364.

4. Groop PH, Thomas MC, Moran JL, Waden J, Thorn LM, Makinen VP, et al. The presence and severity of chronic kidney disease predicts all-cause mortality in type 1 diabetes. Diabetes 2009; 58 (7): 1651-8.

5. Patterson CC, Dahlquist G, Harjutsalo V, Joner G, Feltbower RG, Svensson J, et al. Early mortality in EURODIAB population-based cohorts of type 1 diabetes diagnosed in childhood since 1989. Diabetologia 2007; 50 (12): 2439-42.

6. Skrivarhaug T, Bangstad HJ, Stene LC, Sandvik L, Hanssen KF, Joner G. Long-term mortality in a nationwide cohort of childhood-onset type 1 diabetic patients in Norway. Diabetologia 2006; 49 (2): 298-305.

7. Joner G, Patrick S. The mortality of children with type 1 (insulin-dependent) diabetes mellitus in Norway, 1973-1988. Diabetologia 1991; 34 (1): 29-32.

8. Hermann R, Knip M, Veijola R, Simell O, Laine AP, Akerblom HK, et al. Temporal changes in the frequencies of HLA genotypes in patients with Type 1 diabetes - indication of an increased environmental pressure? Diabetologia 2003; 46 (3): 420-5.

9. Diabetes Epidemiology Research international mortality Study Group. International evaluation of causespecific mortality and IDDM. Diabetes Care 1991; 14: 55-60.

10. Diabetes Epidemiology Research international mortalty Study Group. Major cross-country differences in risk of dying for people with IDDM. Diabetes Care 1991; 14: 49-54.

11. Laing SP, Swerdlow AJ, Slater SD, Botha JL, Burden AC, Waugh NR, et al. The British Diabetic Association Cohort Study, II: cause-specific mortality in patients with insulin-treated diabetes mellitus. Diabet Med 1999; 16 (6): 466-71.

12. Dahlquist G, Kallen B. Mortality in childhood-onset type 1 diabetes: a population-based study. Diabetes Care 2005; 28 (10): 2384-7.

13. Tattersall RB, Gill GV. Unexplained deaths of type 1 diabetic patients. Diabet Med 1991; 8 (1): 49-58.

14. Sovik O, Thordarson H. Dead-in-bed syndrome in young diabetic patients. Diabetes Care 1999; 22 (Suppl 2): B40-2.

15. Beran D, Yudkin JS. Diabetes care in sub-Saharan Africa. Lancet 2006; 368 (9548): 1689-95.

16. Usher-Smith JA, Thompson M, Ercole A, Walter FM. Variation between countries in the frequency of diabetic ketoacidosis at first presentation of type 1 diabetes in children: a systematic review. Diabetologia 2012; 55 (11): 2878-94. 
17. Levy-Marchal C, Patterson CC, Green A. Geographical variation of presentation at diagnosis of type I diabetes in children: the EURODIAB study. European and Dibetes. Diabetologia 2001; 44 (Suppl 3): B75-B80.

18. Skrivarhaug T, Drivvoll AK, Kummernes SJ, Joner G. Diabetic ketoacidosis at onset in children and adolescents with type 1 diabetes in Norway - a nationwide population-based cohort study. Pediatr Diabetes 2012; 13 (Suppl 17): 49.

19. Nathan DM, Zinman B, Cleary PA, Backlund JY, Genuth S, Miller R, et al. Modern-day clinical course of type 1 diabetes mellitus after 30 years' duration: the diabetes control and complications trial/epidemiology of diabetes interventions and complications and Pittsburgh epidemiology of diabetes complications experience (1983-2005). Arch Intern Med 2009; 169 (14): 1307-16.

20. Raile K, Galler A, Hofer S, Herbst A, Dunstheimer D, Busch P, et al. Diabetic nephropathy in 27,805 children, adolescents, and adults with type 1 diabetes: effect of diabetes duration, A1C, hypertension, dyslipidemia, diabetes onset, and sex. Diabetes Care 2007; 30 (10): 2523-8.

21. Svensson M, Nystrom L, Schon S, Dahlquist G. Age at onset of childhood-onset type 1 diabetes and the development of end-stage renal disease: a nationwide population-based study. Diabetes Care 2006; 29 (3): 538-42.

22. Porta M, Sjoelie AK, Chaturvedi N, Stevens L, Rottiers R, Veglio M, et al. Risk factors for progression to proliferative diabetic retinopathy in the EURODIAB Prospective Complications Study. Diabetologia 2001; 44 (12): 2203-9.

23. Dahlquist G, Rudberg S. The prevalence of microalbuminuria in diabetic children and adolescents and its relation to puberty. Acta Paediatr Scand 1987; 76 (5): 795-800.

24. Skrivarhaug T, Bangstad HJ, Stene LC, Sandvik L, Hanssen KF, Joner G. Low risk of overt nephropathy after 24 yr of childhood-onset type 1 diabetes mellitus (T1DM) in Norway. Pediatr Diabetes 2006; 7 (5): 239-46.

25. Skrivarhaug T, Fosmark DS, Stene LC, Bangstad HJ, Sandvik L, Hanssen KF, et al. Low cumulative incidence of proliferative retinopathy in childhood-onset type 1 diabetes: a 24-year follow-up study. Diabetologia 2006; 49 (10): 2281-90.

26. Secrest AM, Becker DJ, Kelsey SF, Laporte RE, Orchard TJ. Cause-specific mortality trends in a large population-based cohort with long-standing childhood-onset type 1 diabetes. Diabetes 2010; 59 (12): 3216-22.

27. Fuller JH, Elford J, Goldblatt P, Adelstein AM. Diabetes mortality: new light on an underestimated public health problem. Diabetologia 1983; 24 (5): 336-41.

28. Andresen EM, Lee JA, Pecoraro RE, Koepsell TD, Hallstrom AP, Siscovick DS. Underreporting of diabetes on death certificates, King County, Washington. Am J Public Health 1993; 83 (7): 1021-4.

29. Laing SP, Swerdlow AJ, Slater SD, Botha JL, Burden AC, Waugh NR, et al. The British Diabetic Association Cohort Study, I: all-cause mortality in patients with insulin-treated diabetes mellitus. Diabet Med $1999 ; 16$ (6): 459-65.

30. International Classification of Diseases, Eight Revision (ICD-8). Oslo: Central Bureau of Statistics of Norway, 1985.

31. International Classification of Diseases, Ninth Revision (ICD-9). Oslo: Central Bureau of Statistics of Norway, 1986.

32. International Classification of Diseases, Tenth Revision (ICD-10). Oslo: Norwegian Board of Health, 2000.

33. Start RD, Bury JP, Strachan AG, Cross SS, Underwood JC. Evaluating the reliability of causes of death in published clinical research. BMJ 1997; 314 (7076): 271.

34. Muhlhauser I, Sawicki PT, Blank M, Overmann H, Richter B, Berger M. Reliability of causes of death in persons with Type I diabetes. Diabetologia 2002; 45 (11): 1490-7.

35. Dorman JS, Laporte RE, Kuller LH, Cruickshanks KJ, Orchard TJ, Wagener DK, et al. The Pittsburgh insulin-dependent diabetes mellitus (IDDM) morbidity and mortality study. Mortality results. Diabetes 1984; 33 (3): 271-6.

36. Colhoun HM, Rubens MB, Underwood SR, Fuller JH. The effect of type 1 diabetes mellitus on the gender difference in coronary artery calcification. J Am Coll Cardiol 2000; 36 (7): 2160-7.

37. Laing SP, Swerdlow AJ, Slater SD, Burden AC, Morris A, Waugh NR, et al. Mortality from heart disease in a cohort of 23,000 patients with insulin-treated diabetes. Diabetologia 2003; 46 (6): 760-5.

38. Harris ND, Heller SR. Sudden death in young patients with Type 1 diabetes: a consequence of disease, treatment or both? Diabet Med 1999; 16 (8): 623-5.

39. Thordarson H, Sovik O. Dead in bed syndrome in young diabetic patients in Norway. Diabet Med $1995 ; 12$ (9): 782-7.

40. Ramsli HM, Therkelsen SP, Sovik O, Thordarson H. [Unexpected and unexplained deaths among young patients with diabetes mellitus]. Tidsskr Nor Lageforen 2004; 124 (23): 3064-5.

41. Sartor G, Dahlquist G. Short-term mortality in childhood onset insulin-dependent diabetes mellitus: a high frequency of unexpected deaths in bed. Diabet Med 1995; 12 (7): 607-11.

42. Asao K, Sarti C, Forsen T, Hyttinen V, Nishimura R, Matsushima M, et al. Long-term mortality in nationwide cohorts of childhood-onset type 1 diabetes in Japan and Finland. Diabetes Care 2003; 26 (7): 2037-42. 
43. Secrest AM, Costacou T, Gutelius B, Miller RG, Songer TJ, Orchard TJ. Association of socioeconomic status with mortality in type 1 diabetes: the Pittsburgh epidemiology of diabetes complications study. Ann Epidemiol 2011; 21 (5): 367-73.

44. Laron-Kenet T, Shamis I, Weitzman S, Rosen S, Laron ZV. Mortality of patients with childhood onset (0-17 years) Type I diabetes in Israel: a population-based study. Diabetologia 2001; 44 (Suppl 3): B81-B86.

45. Podar T, Solntsev A, Reunanen A, Urbonaite B, Zalinkevicius R, Karvonen M, et al. Mortality in patients with childhood-onset type 1 diabetes in Finland, Estonia, and Lithuania: follow-up of nationwide cohorts. Diabetes Care 2000; 23 (3): 290-4.

46. Barcelo A, Bosnyak Z, Orchard T. A cohort analysis of type 1 diabetes mortality in Havana and Allegheny County, Pittsburgh, PA. Diabetes Res Clin Pract 2007; 75 (2): 214-9.

47. Urbonaite B, Zalinkevicius R, Green A. Incidence, prevalence, and mortality of insulin-dependent (type 1) diabetes mellitus in Lithuanian children during 1983-98. Pediatr Diabetes 2002; 3 (1): 23-30. 